Research Square prints are preliminary reports that have not undergone peer review.

They should not be considered conclusive, used to inform clinical practice, or referenced by the media as validated information.

\title{
The Effect of Hatha Yoga on Low Back Pain and Sleep Quality in Nulliparous Pregnant Women: A Clinical Trial Study
}

\section{peyman namdar}

Qazvin University of Medical Sciences Qazvin Medical School

\section{narges hoseini}

Qazvin University of Medical Sciences

leila dehghankar

Qazvin University of Medical Sciences

leili yekefallah ( $\square$ leili_fallah@yahoo.com)

Qazvin University of Medical Sciences https://orcid.org/0000-0001-7425-9451

\section{Research}

Keywords: Hatha yoga, low back pain, sleep quality, pregnant women, nulliparous

DOI: https://doi.org/10.21203/rs.3.rs-78249/v1

License: (c) (i) This work is licensed under a Creative Commons Attribution 4.0 International License. Read Full License 


\section{Abstract}

\section{Background}

"Sleep quality disorder" and "low back pain" are some of the most common complaints of pregnant women during pregnancy and disturb their daily activities. Currently, there are not enough interventions for these symptoms. Recently, the sport of yoga, one of the stretching sports and therapeutic methods, has attracted the attention of rehabilitation specialists. This study aimed to determine the effect of Hatha yoga on low back pain and sleep quality in nulliparous pregnant women.

\section{Methods}

This controlled clinical trial study was performed on 60 eligible nulliparous pregnant women at the gestation age of 24 to 28 weeks with normal pregnancy in the gynecology clinic of Kowsar Hospital in Qazvin city, Iran. The samples were selected using convenience sampling and were assigned to intervention and control groups via random sampling without replacement. In addition to receiving routine pregnancy care by referring to the gynecology clinic of the hospital, the intervention group attended Hatha yoga classes twice a week (each session lasting 75 minutes) at the Hatha yoga specialized sports club from week 26 to week 37 of their pregnancy. A demographic information questionnaire, a visual pain scale, and the Pittsburgh Sleep Quality Index were used to collect information. In addition, SPSS software (version 24) and descriptive and inferential statistics were used to analyze the data. The significance level of all the tests was considered to be $p<0.05$.

\section{Results}

Using Wilcoxon tests, the comparison of low back pain in the intervention group before (with the p-value of 0.057 ) and after (with the p-value of 0.172 ) the study showed that there was no significant difference between the pain scores in the intervention group. Moreover, using Wilcoxon tests, the comparison of the sleep quality score in the intervention group before (with the p-value of 0.007 ) and after (with the p-value of 0.001 ) the study indicated that there was a significant difference in the sleep quality scores in the intervention group.

\section{Conclusion}

Based on the results of the study, it can be said that Hatha yoga did not have a significant effect on the low back pain scores in the intervention group, however, it had a significant effect on their sleep quality. According to the findings of this study, the correct and regular use of Hatha yoga under the supervision of a specialist instructor can be valuable for pregnant women in their second trimester due to its being noninvasiveness and applicable.

Trial registration 